\title{
ANALISIS PERFORMA KINERJA TURBIN ANGIN SAVONIUS 2 SUDU
}

\author{
Basuki $^{1}$, Mohammad Munib Rosadi ${ }^{2}$, Retno Eka Pramitasari ${ }^{3}$, Fajar Satriya Hadi ${ }^{4}$ \\ Fakultas Teknik,Universitas Hasyim Asy'ari \\ ${ }^{1}$ ukibas02its@gmail.com \\ 2munib.rosadi@gmail.com \\ ${ }^{3}$ retnomita91@gmail.com \\ ${ }^{4}$ swedia0001@gmail.com
}

\begin{abstract}
Renewable energy sources are energy sources that can replace the use and use of fossil energy sources where they are very abundant and have not been widely used for their existence. Therefore, to bring up new ideas in terms of creating or changing renewable energy, there needs to be a match between the education curriculum and market needs. So to arouse the enthusiasm and motivation of students in the teaching and learning process, especially in the energy conversion machine course for mechanical engineering students, it needs media and learning methods. The purpose of this research is to know how to design a savonius wind turbine props, and the working principle, and analyze the performance of the wind turbine. The sequence of the process of making savonius wind turbines comprises of making: (1) frameworks and machine tables, (2) chimneys, (3) duct, (4) installation of fans, (5) turbine holder (6) two blades savonius turbines and servo motor holder. The working principle of a wind turbine is a turbine rotation caused by the wind being transmitted to the generator rotor, where the generator has a copper coil that functions as a stator which will produce an electric voltage. From this research produced a savonius wind turbine tool which is used as a learning medium in the Mechanical Engineering Study Program. From the results of savonius type wind turbine test equipment produced the following data: maximum voltage of 10 volts, wind speed of $8.5 \mathrm{~m} / \mathrm{s}$, rotor generator rotation of 2734 rpm and power of 340 watts.
\end{abstract}

Keywords: Energy, Turbine, Wind, Savonius

\begin{abstract}
Abstrak: Sumber energi terbarukan adalah sumber energi yang dapat menggantikan pemanfaatan dan penggunaan sumber energi fosil dimana keberadaannya sangat melimpah dan belum banyak digunakan akan keberadaannya. Oleh karena itu untuk memunculkan ide ide baru dalam hal menciptakan atau mengubah energi terbarukan ini perlu adanya kesesuaian antara kurikulum pendidikan dengan kebutuhan pasar. Maka untuk membangkitkan semangat dan motivasi mahasiswa dalam proses belajar mengajar khususnya dalam mata kuliah Mesin Konversi Energi bagi mahasiswa teknik mesin maka perlu media dan metode pembelajaran. Tujuan dari penelitian ini adalah mengetahui cara mendesain sebuah alat peraga turbin angin savonius, mengetahui prinsip kerja, dan menganalisa dari performa kinerja dari turbin angin tersebut. Urutan proses pembuatan turbin angin savonius adalah (1) pembuatan kerangka dan meja mesin, (2) pembuatan cerobong angin, (3) pembuatan duct, (4) pemasangan kipas angin, (5) pembuatan dudukan turbin, (6) pembuatan turbin savonius 2 sudu dan pembuatan dudukan motor servo. Prinsip kerja turbin angin adalah putaran turbin yang disebabkan oleh angin diteruskan ke rotor generator, dimana generator memiliki lilitan tembaga yang berfungsi sebagai stator yang akan menghasilkan tegangan listrik. Dari penelitian tersebut dihasilkan sebuah alat turbin angin savonius yang digunakan sebagai media pembelajaran di Program Studi Teknik Mesin. Dari hasil pengujian alat turbin angin tipe savonius menghasilkan data sebagai berikut: tegangan maksimal sebesar 10 volt, kecepatan angin $8.5 \mathrm{~m} / \mathrm{s}$, putaran rotor generator $2734 \mathrm{rpm}$ dan daya sebesar 340 watt.
\end{abstract}

Kata kunci: Energi, Turbin, Angin, Savonius 


\section{Pendahuluan}

Mengingat kebutuhan listrik di Indonesia pada saat ini masih bergantung pada energi fosil yang jumlahnya sangat terbatas. Indonesia diprediksi akan mengalami krisis setidaknya sebesar 1000 megawatt di tahun 2018 (http://www.hartech.co.id). Oleh karena itu perlu adanya temuan temuan energi alternatif atau energi terbarukan yang bisa membantu mengalihkan penggunaan energi listrik dari fosil ke energi terbarukan. Oleh karena itu seharusnya segera dibangun pembangkit listrik yang memanfaatkan energi terbarukan. Pengamat energi, Marwan Batubara mengatakan pemanfaatan energi terbarukan sebagai sumber pasokan listrik akan menghemat devisa dan anggaran negara (http://www.liputan6.com).

Sumber energi terbarukan merupakan sumber energi yang jumlahnya sangat tak terbatas dimana keberadaannya sangat melimpah dan belum banyak digunakan akan keberadaannya. Ada beberapa macam energi terbarukan antara lain: energi matahari, energi geothermal, energi angin, energi pasang surut, energi biomassa, energi biofuel, energi gelombang

(https://geothermalindonesia.com).

Pembangkit listrik tenaga angin adalah sebuah pembangkit yang bisa menghasilkan listrik yang memanfaatkan energi angin. Munculnya angin terjadi ketika udara bergerak dari tekanan tinggi ke tekanan yang rendah karena dipengaruhi oleh panas matahari (Pangestu, 2017). Prinsip kerjanya adalah angin memutar sudu pada turbin angin, kemudian sudu turbin tersebut dihubungkan ke generator. Pada bagian ini terjadi konversi energi kinetik dari angin akan dirubah menjadi energi mekanik pada generator dan akan menghasilkan listrik (Sumiati,2014).
Listrik yang dihasilkan dari pembangkit tersebut akan dimanfaatkan pada beban seperti lampu dan alat perabot rumah tangga. Pada dasarnya turbin angin ini dibedakan menjadi dua berdasarkan model poros yaitu turbin angin dengan poros horizontal (HAWT) dan turbin angin poros vertikal (VAWT) (Wachid, 2018).

Pada penelitian ini akan membuat alat turbin angin tipe savonius 2 sudu yang merupakan salah satu contoh dari turbin angin poros vertikal. Pada prinsipnya turbin angin savonius ini memanfaatkan gaya hambat (Nahkoda,2015). Setelah dibuat turbin angin savonius 2 sudu, kemudian akan dianalisa performa kinerja turbin angin savonius. Alat peraga turbin angin savonius akan dijadikan sebagai sarana pendukung untuk mata kuliah Mesin Konversi Energi pada jurusan Teknik Mesin Universitas Hasyim Asy'ari. Sehingga kehadiran alat turbin angin savonius diharapkan mampu membantu atau dijadikan acuan dalam proses belajar tentang proses konversi energi.

Sehingga penulis tertarik untuk meneliti penelitian ini yang berjudul “ Analisis Performa Kinerja Turbin Angin Savonius 2 Sudu". Hal ini mengingat pentingnya alat atau prototype mesin pengkonversi energi, dengan tujuan agar mahasiswa secara langsung memahami fungsi beberapa komponen sistem pembangkit.. Alat ini juga nantinya akan digunakan sebagai media peraga dalam mata kulian Mesin Konversi Energi.

\section{Metode}

Metode yang digunakan dalam penelitian ini adalah menggunakan metode Riset and Development, kemudian dilanjutkan dengan eksperimen. Tempat pelaksanaan kegiatan ini di Laboratorium Pengelasan Teknik Mesin Universitas Hasyim 
Asy'ari. Alat dan bahan yang digunakan antara lain:

Alat terdiri dari: turbin angin savonius, fan blower, generator / motor servo, anemometer, multimeter, tachometer, gergaji besi, mesin las listrik, gergaji kayu, mistar atau meteran.

Bahan terdiri dari: turbin savonius, duct, kerangka mesin, sarangan angin, triplek, kabel, elektroda las, besi, besi siku.

Prosedur Pembuatan yaitu ada beberapa prosedur dalam pembuatan mesin turbin angin savonius antara lain:

1. Pembuatan turbin angin savonius Langkah-langkahnya:

a. Menyiapkan software inventor

b. Menggambar turbin angin savonius sesuai spesifikasi

c. Pembuatan turbin savonius dari bahan PVC

2. Pembuatan kerangka mesin turbin angin savonius

Langkah-langkahnya :

a. Menyiapakan software inventor

b. Menggambar kerangka mesin sesuai dengan spesifikasi yang telah ditentukan

c. Pembuatan kerangka mesin dari bahan besi siku sesuai dengan spesifikasi yang telah ditentukan

3. Pembuatan duct

a. Menyiapkan software inventor

b. Menggambar duct dengan inventor sesuai dengan spesifikasi yang telah ditentukan

c. Pembuatan duct dari bahan triplek

4. Pembuatan sarangan angin

a. Menyiapkan software inventor

b. Menggambar saringan angin pada inventor

c. Pembuatan saringan dari sarangan kawat

Prosedur pengujian yang

dilakukan antara lain: fan diletakkan didalam sistem duct pada jarak $50 \mathrm{~cm}$ dari outlet sistem duct. Pada bagian outlet sistem duct dipasang kawat mesh untuk membuat distribusi aliran yang seragam dan mengurangi fluktuasi pada outlet. Voltase input yang menuju fan diatur dengan membaca tegangan AC voltage regulator di multimeter. Jarak poros turbin angin dan output fan $60 \mathrm{~cm}$ pada bagian downstream. Putaran dari poros turbin direduksi dengan gearbox yang memiliki perbandingan 1:3 dan ditransmisikan ke generator. Putaran turbin (RPM) diukur dengan menggunakan digital photo tachometer. Tegangan dan arus dari generator diukur menggunakan multitester. Pengukuran kecepatan angin dilakukan dengan menggunakan anemometer digital. Berikut dibawah ini gambar pengujian eksperimen:

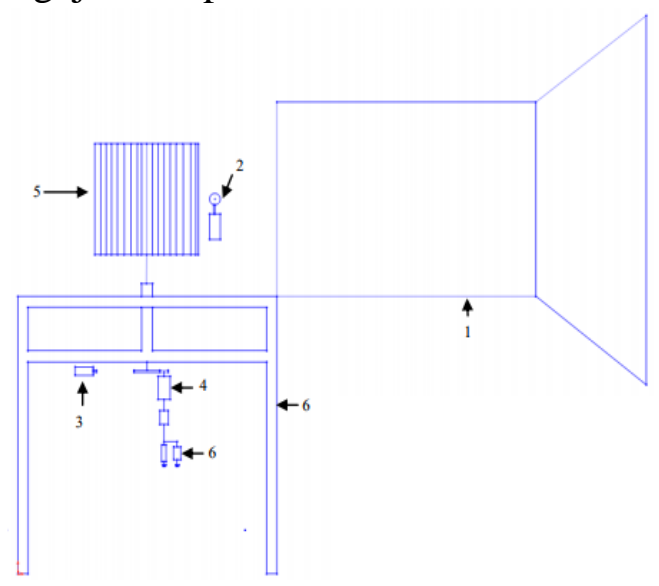

Gambar 1. Pengujian Eksperimen

Keterangan:

1. Fan dan sistem $d u c t$

2. Anemometer

3. Tachometer

4. Generator dan rangkaian pembebanan

5. Turbin

6. Multimeter

7. Frame

Berikut ini merupakan tahapantahapan dalam pengujian:

1. Menyalakan fan.

2. Mengukur dan mencatat kecepatan angin pada bagian depan fan dengan menggunakan anemometer. 
3. Mengukur dan mencatat putaran (RPM) pada poros turbin angin dengan tachometer.

4. Mengukur dan mencatat tegangan dan arus pada generator dengan menggunakan multimeter.

5. Mengulangi langkah 2 sampai 4 sebanyak tiga kali.

Diagram alir penelitian

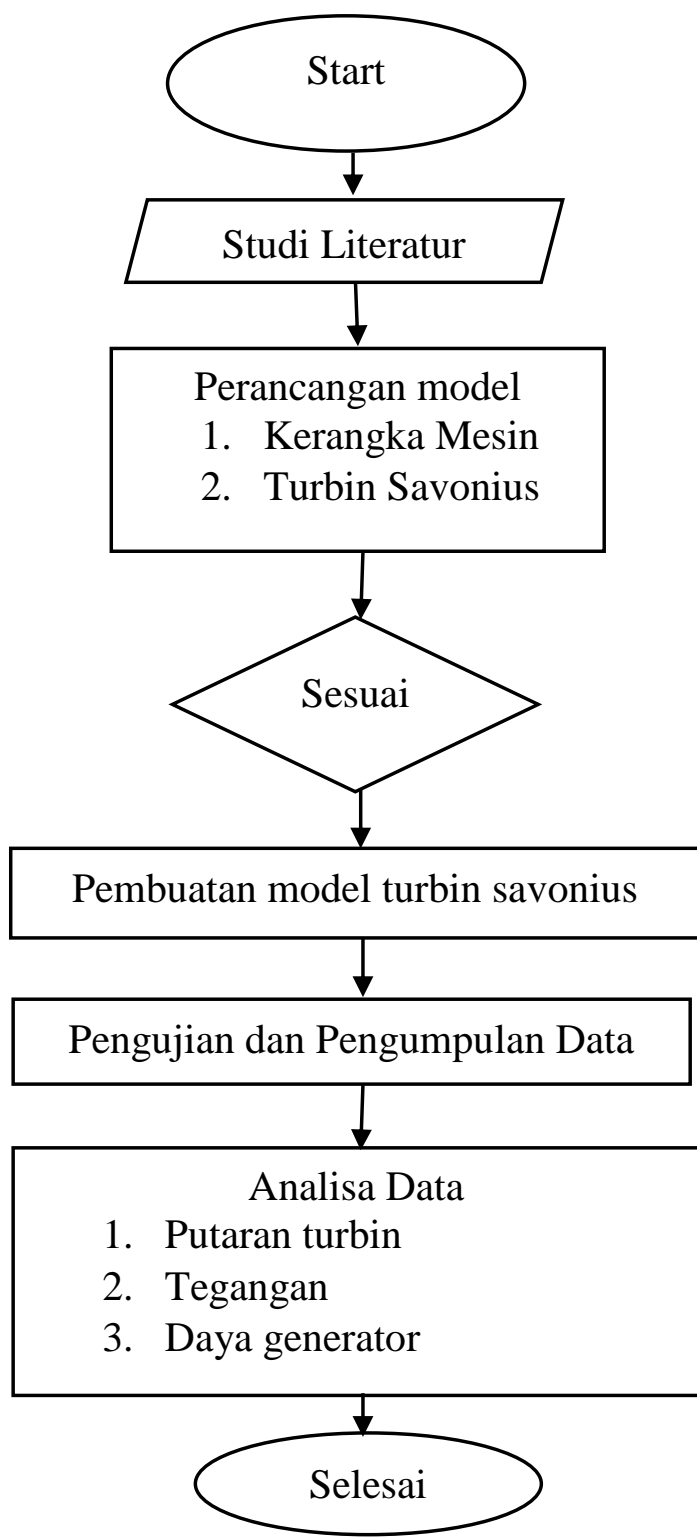

Gambar 2. Diagram Alir Penelitian
Gambar 3 berikut ini merupakan alat turbin angin.

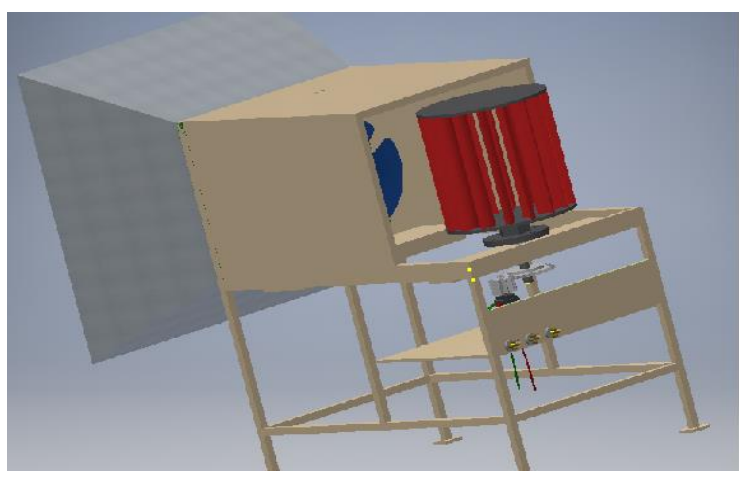

Gambar 3. Alat Turbin Angin

\section{Hasil dan Pembahasan}

Adapun hasil dari penelitian ini adalah:

1. Tegangan

Pada gambar 4 menunjukkan hubungan antara tegangan dan Rpm pada alat turbin angin savonius dua sudu. Dari gambar dibawah menunjukkan ada pengaruh antara putaran generator dengan daya listrik yang dihasilkan. Naiknya putaran generator diikuti naiknya daya listrik, begitu sebaliknya jika putaran generator rendah maka daya yang dihasilkan juga semakin kecil.

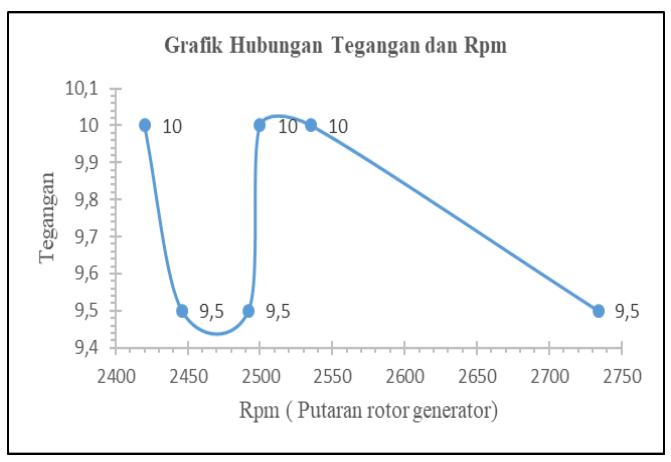

Gambar 4. Grafik Hubungan Tegangan dengan RPM

\section{Kecepatan}

Pada gambar 5 menunjukkan hubungan kecepatan angin dengan waktu, didapatkan data bahwa bersifat 
fluktuatif. Dari data tersebut bisa dilihat ketika pengukuran kecepatan dimulai jam 09.50 sampai jam 10.10 mengalami penurunan kecepatan, kemudian ketika jam 10.20 sampai jam 11.40 mengalami kenaikan kecepatan. Hal ini bisa ditarik kesimpulan bahwa faktor lingkungan sangat berpengaruh pada pengukuran kecepatan angin.

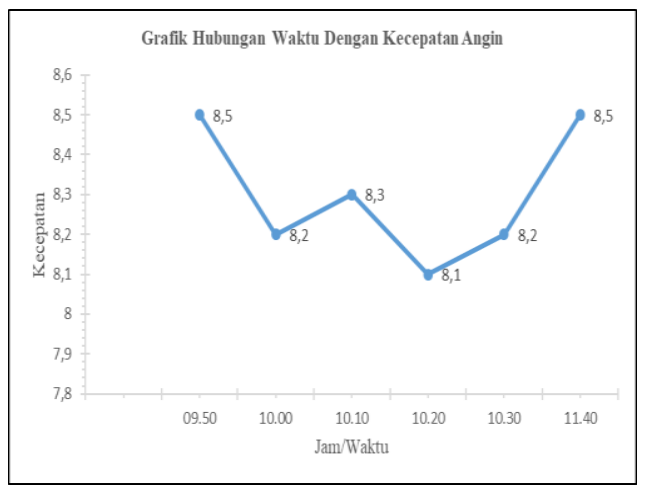

Gambar 5. Grafik Hubungan Kecepatan Angin dengan Waktu

\section{RPM (Putaran rotor generator)}

Pada Gambar 6 menunjukkan hubungan antara Rpm dengan kecepatan angin, kecepatan angin sangat berpengaruh pada putaran rotor generator (rpm). Semakin tinggi kecepatan angin yang dihasilkan maka semakin tinggi pula putaran rotor generator yang dihasilkan, maka hal ini juga berpengaruh pula pada tegangan yang dihasilkan.

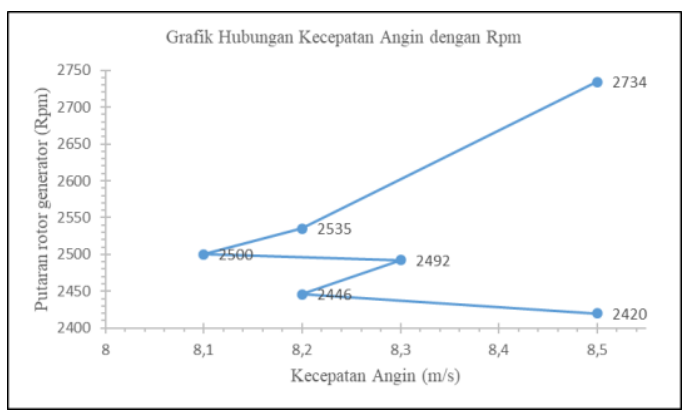

Gambar 6. Grafik Hubungan Kecepatan Angin dengan RPM

\section{Daya}

Gambar 7 menunjukkan hubungan antara kecepatan angin dengan daya yang dihasilkan. Dari data tersebut diperoleh hubungan antara kecepatan angin berbanding lurus dengan daya yang dihasilkan. Semakin tinggi kecepatan angin maka semakin tinggi pula daya yang dihasilkan.

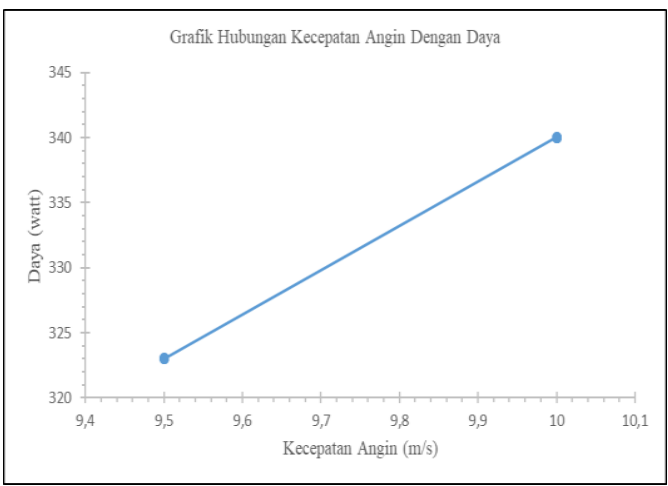

Gambar 7. Grafik Hubungan Kecepatan Angin dengan Daya

\section{Simpulan}

Setelah dilakukan percobaan atau penelitian, maka dapat ditarik kesimpulan sebagai berikut :

1. Turbin angin savonius 2 sudu mampu menghasilkan performa kinerja berupa tegangan sebesar 10 volt, daya 340 watt pada kecepatan angin $8,5 \mathrm{~m} / \mathrm{s}$ dan putaran rotor generator $2734 \mathrm{rpm}$.

2. Dari penelitian tersebut terbukti bahwa angin mampu dirubah menjadi energi listrik dengan alat bantu turbin yang dihubungkan dengan generator. Ditemukan energi ini dapat digunakan sebagai pengganti atau alternatif dari energi fosil dan dapat dimanfaatkan untuk memenuhi kebutuhan listrik dalam rumah tangga. 


\section{Daftar Pustaka}

Nakhoda, Y. I. and C. Saleh. (2015). Rancang Bangun Kincir Angin Sumbu Vertikal Pembangkit Tenaga Listrik Portabel. Seminar Nasional Sains dan Teknologi Terapan III Institut Teknologi Adhi Tama Surabaya. ISBN 978-602-98569-1-0.

Pangestu, R. (2017). Turbin Angin Vertikal Savonius Bertingkat Membentuk Helix. 10.13140/RG.2.2.14852.73600.

Sumiati, R. and A. Zamri (2013). "Rancang Bangun Miniatur Turbin Angin Pembangkit Listrik untuk Media Pembelajaran." Jurnal Teknik Mesin. Vol. 3, No. 2.

Wachid, A. and I. Herlamba Siregar (2018). "Study Experimental Turbin Angin Savonius 2 tingkat Dengan Penambahan Drag Reducing Pada Returning Blade (Studi Kasus Pada 2 Blade Pertingkat)." Jurnal Pendidikan Teknik Mesin. Vol. 7, No. 1.

http://www.hartech.co.id. Diakses tanggal 15 Mei 2018.

http://www.liputan6.com). Diakses tanggal 15 Mei 2018.

https://geothermalindonesia.com.

Diakses tanggal 15 Mei 2018 